\title{
Effect of Atrial Natriuretic Peptide on Vascular Permeation in the Ovine Fetus
}

\author{
MICHAEL SILBERBACH, DEBRA F. ANDERSON, MARK D. RELLER, AND LOWELL E. DAVIS \\ The Clinical Care Center For Congenital Heart Disease. The Department of Physiology: and The Department of \\ Obstetrics and Ginecology, Oregon Health Sciences University, Portland. Oregon 97201-3098
}

\begin{abstract}
To study the effect of atrial natriuretic peptide (ANP) on vascular permeation of albumin in the fetus, ANP (167-600 $\mathrm{ng} / \mathrm{min})$ was infused into eight ovine fetuses and saline vehicle was infused into eight twin controls (gestational age $127 \pm 3 \mathrm{~d}$ ) over a 50 -min period. Using two different radiolabeled albumin markers, we determined the tissue to blood isotope ratio (TBIR), an index of albumin permeation, and the albumin clearance. Although ANP had no hemodynamic effect, a marked increase in the hematocrit was observed in ANP-infused fetuses compared with initial values $(0.37 \pm 0.04$ vs $0.42 \pm 0.04, p<0.005)$ but was unchanged in the twin fetuses receiving saline vehicle $(0.35 \pm 0.03$ versus $0.35 \pm 0.02)$. TBIR and albumin permeation were increased in combined tissues of ANP. infused fetuses compared with saline controls (TBIR: 1.49 \pm 0.58 versus $1.29 \pm 0.3, p<0.001$; albumin clearance: $1091 \pm 1279$ versus $827 \pm 1464 \mathrm{~nL} / \mathrm{g} / \mathrm{min}, p<0.01$ ). In individual tissues, TBIR was significantly increased in skin $(2.88 \pm 0.67$ versus $1.55 \pm 0.35, p<0.02)$, muscle $(1.6 \pm$ 0.27 versus $1.24 \pm 0.26, p<0.02)$, adrenal $(1.33 \pm 0.10$ versus $1.13 \pm 0.15, p<0.02)$, bone $(1.67 \pm 0.45$ versus $1.20 \pm 0.40, p<0.02)$, kidney $(1.52 \pm 0.25$ versus $1.24 \pm$ $0.26, p<0.03)$, and gut $(1.69 \pm 0.20$ versus $1.39 \pm 0.34$, $p<0.03$ ). Albumin clearance was higher in most tissues but reached statistical significance only in skin $(2135 \pm$ 944 versus $775 \pm 847 \mathrm{~nL} / \mathrm{g} / \mathrm{min}, p<0.05)$ and bone $(1012$ \pm 1107 versus $428 \pm 482 \mathrm{~nL} / \mathrm{g} / \mathrm{min}, p<0.05)$. We conclude that overall vascular filtration is higher in the fetus than the adult. Infusion of ANP causes fetal hemoconcentration, decreases blood volume, and enhances vascular permeation of albumin in most tissues, particularly fetal skin. We speculate that the cardiac atria, by secreting $A N P$, participate in blood volume regulation by maintaining a critical balance between the intravascular and extravascular fluid compartments. Dysregulation of the ANP system might result in fetal hydrops. (Pediatr Res 35: 555-559, 1994)
\end{abstract}

\section{Abbreviations}

ANP, $\alpha$-human atrial natriuretic polypeptide

TBIR, tissue-to-blood-isotope ratio

$I_{p}$, tissue-permeating isotope

$I_{b v}$, blood volume-marking isotope

Received May 17, 1993; accepted December 8, 1993.

Correspondence and reprint requests: Michael Silberbach, M.D. Clinical Care Center For Congenital Heart Disease, Oregon Health Sciences University, 3181 SW Sam Jackson Park Rd., UHN 60, Portland, OR 97201-3098.

Supported in part by a grant-in-aid from the American Heart Association Inc. Oregon affiliate (M.S.), the National Heart Lung and Blood Institute (Grant HL45043 and HL42893), and the National Institute of Child Health and Human Development (HD01051-01).
In the adult, the primary action of ANP is to decrease blood volume by increasing urine flow (1). ANP infusion can also lower blood volume in anephric experimental animals (2-4), suggesting that it causes extravasation of plasma in the adult. Other recent work has implicated ANP in fetal blood volume regulation. ANP infusion into the fetus increases hematocrit and decreases blood volume, even though fetal urine output is only minimally increased (5). Consistent with this finding is the observation by Robillard et al. (6) that ANP causes hemoconcentration even though responsiveness of the fetal kidney to ANP is decreased compared with that of the neonatal and adult kidney in animals. These data raise the possibility that, in the presence of the functionally immature fetal kidney, the blood volume lowering effect of ANP in the fetus may be mediated primarily through vascular permeation, as initially suggested by Clark (7). Furthermore, the pathophysiologic implications of elevated circulating ANP concentration $(8-10)$ in the disorder of fetal fluid balance known as fetal hydrops warrants investigation of the role of this hormone in the transport of fluid and protein from the vascular compartment into other tissues. In the present report, we describe the effect of ANP on regional albumin permeation in the chronically instrumented, unanesthetized, late gestation fetal lamb.

\section{MATERIALS AND METHODS}

Surgical preparation. All care and procedures were approved by the Oregon Health Sciences University Animal Care and Use Committee. Sterile surgeries were performed on eight ewes carrying twin fetuses at $122 \pm 3 \mathrm{~d}$ gestation (term $=146 \mathrm{~d}$ ). General anesthesia was induced using i.v. diazepam and ketamine; the ewe was intubated and anesthesia was maintained with halothane and $50 \% \mathrm{~N}_{2} \mathrm{O}-50 \% \mathrm{O}_{2}$. After the uterus was exposed through a midline abdominal incision, a separate incision was made for each twin in a cotyledon-free uterine area to permit access to the fetal head and neck or hind limbs. In each twin, polyvinyl catheters ( $1.0 \mathrm{~mm}$ inner diameter) were inserted into the jugular vein or femoral vein and were positioned so that their tips were in the right atrium or abdominal vena cava for the infusion of ANP or vehicle, measurement of central venous pressure, and infusion of radiolabeled tracers. Catheters were inserted into the carotid artery or the femoral artery for measurement of arterial blood pressure and withdrawal of blood, and a catheter was positioned in the amniotic space for reference pressure measurements. At the end of surgery, 1 million $U$ of penicillin $G$ and $250 \mathrm{mg}$ of streptomycin were administered directly into the amniotic fluid. All catheters were exteriorized through an s.c. tunnel and placed in a cloth pouch on the ewe's flank. After recovery from anesthesia, the ewes were kept in a restricted area and fed a standard diet. On the first and second postoperative days, the ewes received daily intramuscular injections of streptomycin $(1 \mathrm{~g})$ and ampicillin $(800 \mathrm{mg})$

Experimental protocol. Baseline data were obtained after a recovery period of $4-5 \mathrm{~d}$ (gestational age $127 \pm 3 \mathrm{~d}$ ). Arterial blood was collected anaerobically in heparinized plastic syringes, and $\mathrm{pH}, \mathrm{PCO}_{2}$, and $\mathrm{PO}_{2}$ were measured at $39^{\circ} \mathrm{C}$ (IL 1312 blood 
gas analyzer, Instrument Laboratories, Lexington, MA). The hematocrit was determined in duplicate. Mean arterial and central venous pressure were measured with Statham $p-23$ Db strain gauge transducers, recorded on a six-channel polygraph recorder (Gould Instruments, Cleveland, $\mathrm{OH}$ ), and referenced to amniotic fluid pressure. Percent change in blood volume was calculated from the change in hematocrit. Either ANP $[167 \mathrm{ng} / \mathrm{min}(n=$ 2) or $600 \mathrm{ng} / \mathrm{min}(n=6)(\alpha$-atrial natriuretic polypeptide 1-28, Peninsula Laboratories Inc., Belmont, CA] or saline vehicle ( $n$ $=8$ ) at a flow rate of $0.1 \mathrm{~mL} / \mathrm{min}$ was infused for a total of 50 min (Fig. 1). Thus, eight fetuses received ANP and eight matched twin controls received saline vehicle. A bolus of either ${ }^{131}$ I-BSA or ${ }^{125}$ I-BSA (Iso-Tex Diagnostics, Friendswood, TX), injected i.v. into both fetuses $20 \mathrm{~min}$ after the beginning of the ANP or vehicle infusions, served as the $I_{p}$. Two minutes before the end of the experiment (48 min after initiating ANP or vehicle) either ${ }^{131} \mathrm{I}-\mathrm{BSA}$ or ${ }^{125} \mathrm{I}-\mathrm{BSA}$ (the $\mathrm{I}_{\mathrm{hv}}$ ) was injected simultaneously into both fetuses. For each experiment, if ${ }^{131} \mathrm{I}$-BSA was $\mathrm{I}_{\mathrm{p}}$, then ${ }^{125} \mathrm{I}-$ BSA served as $I_{h v}$ and vice versa. Four arterial blood samples (2 $\mathrm{mL}$ per sample, total blood withdrawn less than $2 \%$ of estimated blood volume) were obtained at time $0,30,40$, and $50 \mathrm{~min}$ to determine hematocrit and to quantify tracer radioactivity. At the end of the ANP or vehicle infusion $(50 \mathrm{~min})$, the fetuses were killed with an i.v. injection of euthanasia solution. Close attention was paid to achieving simultaneous fetal death. The ewe was then killed and the fetuses were rapidly delivered, towel dried, and weighed. The fetal chests were opened, the hearts were excised, and various tissues were removed for quantification of tracers by gamma spectrometry. Before counting, each tissue was rinsed briefly in saline to remove any blood contaminating tissue surfaces and was then weighed.

The TBIR, an index of albumin permeation, has been described by Kilzer $e t$ al. (11). In the present investigation, radiolabeled albumin was used for the blood volume marker rather than radiolabeled red blood cells, a modification suggested by Williamson et al. (2). The TBIR was determined according to the following equation:

$$
\operatorname{TBIR}=\left[\mathrm{I}_{\mathrm{p}} / \mathrm{I}_{\mathrm{hv}}\right] \mathrm{t} \div\left[\mathrm{I}_{\mathrm{p}} / \mathrm{I}_{\mathrm{hv}}\right] \mathrm{b}
$$

where the quotient of the $I_{p}$ radioactivity and the $I_{b v}$ radioactivity in each tissue $(\mathrm{t})$ is divided by the quotient of the same isotopes in the arterial blood sample (b) drawn just before the conclusion of the experiment. A ratio greater than 1 indicates that the volume of distribution of $I_{p}$ in the tissues is greater than in the blood and therefore indicates permeation of the vasculature by albumin into the extravascular space. Plasma albumin clearance was expressed as $\mathrm{nL} / \mathrm{g} / \mathrm{min}$ and was calculated according to method described by Williamson et al. (2):

Albumin clearance $(\mathrm{mL} / \mathrm{g} / \mathrm{min})$

$$
=\frac{I_{p_{l}}\left[\left(I_{p} / I_{h v}\right)_{l}-\left(I_{p} / I_{h v}\right)_{h}\right]}{\text { time average mean } I_{p} \text { counts in blood }} \div 30 \text { min }
$$

where the tissue radioactivity of the $I_{p}$ per gram $\left(I_{t}\right)$ was corrected for the intravascular content of this tracer on the basis of the
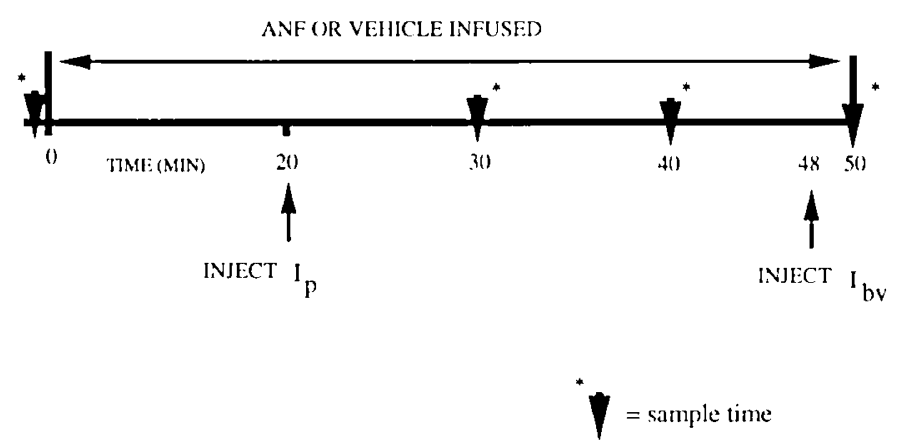

Fig. 1. Experimental protocol. difference in the ratio of the radioactivity of the $I_{p}$ and the $I_{b v}$ in the tissue $\left(I_{p} / I_{b v}\right)_{t}$ and the ratio of the $I_{p}$ and the $I_{b v}$ in the terminally drawn blood sample $\left(I_{\mathrm{p}} / \mathrm{I}_{\mathrm{bv}}\right)_{\mathrm{b}}$. The tissue content of the $I_{p}$ in excess of the vascular content of the $I_{p}$ represents the amount of the $I_{\mathfrak{p}}$ that has traveled into the tissue space. This radioactivity was divided by the mean plasma concentration of $I_{p}$ (derived from the blood samples taken at 10,20, and $30 \mathrm{~min}$ after injection of the tracer, assuming a linear decrease of $I_{p}$ from plasma to tissue with time). It was then divided by the duration of time the tracer was permitted to travel into tissues $(30 \mathrm{~min})$ to obtain the albumin clearance.

TBIR data are presented for 14 fetuses (seven twin pairs). In one of the eight twin pairs, an error in isotope administration prevented calculation of the TBIR. Albumin clearance was completed in 10 fetuses (five twin pairs). In seven twin pairs, fetal death at the end of the experiment occurred simultaneously. In one set of twins, death occurred 10 min later in the twin receiving ANP, thus allowing a longer $I_{p}$ circulation time and potentially increasing albumin permeation. For this fetus, TBIR was calculated in two different ways: $l$ ) by assuming circulation time was the same in both fetuses, and 2) by assuming that permeation continued during the additional time before fetal death and extrapolating the tissue counts back to the 30 -min post-albumin injection time point. The statistical analysis of TBIR was not different with or without the extrapolation for this single fetus; therefore, these data were not excluded.

Data tabulation and statistical analysis. Quantification of radiolabeled tracers in tissues and blood was performed in a gamma spectrometer (Micrad, Knoxville, TN). The data were corrected for background and spillover before determination of TBIR and clearance. At least 10000 counts were obtained for each isotope. Data were analyzed using the MacSS (Statsoft, Tulsa, OK) on a Macintosh SE computer. All data are expressed as mean \pm SD. The effects of ANP or saline vehicle on blood volume through time were explored with analysis for repeated measures. When analysis of variance demonstrated significant differences, paired contrasts were performed to compare the baseline (time 0 ) values with subsequent time points (withingroup comparison). Hemodynamic and albumin permeation data were explored using the Wilcoxon matched pairs test. Statistical significance was presumed in all cases at $p<0.05$.

\section{RESULTS}

At the beginning of the experiment before any infusion was begun, arterial blood gases were similar when the twins were compared (Table 1). Body weights between the two groups were not different at autopsy $(2.98 \pm 0.45 \mathrm{~kg}$ versus $2.92 \pm 0.3 \mathrm{~kg})$. The hematocrit was significantly increased in ANP-infused fetuses compared with initial values $(0.37 \pm 0.04$ versus $0.42 \pm$ $0.04 ; p<0.005$ ), whereas the hematocrit remained statistically unchanged in the twin fetuses who simultaneously received saline vehicle for $50 \mathrm{~min}(0.35 \pm 0.03$ versus $0.35 \pm 0.02)$. Furthermore, although the hematocrit differences between ANP fetuses and saline twins were initially not different, after $50 \mathrm{~min}$ a significant increase in hematocrit occurred in the ANP twins $(p<0.005)$. Other than its hemoconcentrating effect, the ANP infusion had no other significant hemodynamic influence.

Over time, ANP significantly reduced blood volume by a maximum of $11.1 \pm 5.3 \%$ after $40 \mathrm{~min}(p<0.02)$ compared with an increase of $1.4 \pm 3.7 \%$ in the control twins (Fig. 2). Beyond $40 \mathrm{~min}$, blood volume in the ANP group did not change. However, a minimal, nonsignificant increase in blood volume for the group receiving saline vehicle continued to be observed until the end of the experiment.

The effect of ANP on vascular permeation of radiolabeled albumin was estimated by calculating the TBIR and the albumin clearance (Fig. 3). For both TBIR and albumin clearance, ANP significantly increased permeation when tissues were grouped together and compared with saline vehicle [TBIR $(n=77): 1.49$ 
Table 1. Arterial blood gases and hemodynamic data during the control state and after 50 min of infiusion of ANP or saline vellicle*

\begin{tabular}{|c|c|c|c|c|}
\hline & \multicolumn{2}{|c|}{ Saline vehicle } & \multicolumn{2}{|c|}{ ANP } \\
\hline & $0 \mathrm{Min}$ & $50 \mathrm{Min}$ & $0 \mathrm{Min}$ & $50 \mathrm{Min}$ \\
\hline $\mathrm{pH}$ & $7.36 \pm 0.03$ & & $7.36 \pm 0.01$ & \\
\hline $\mathrm{PCO}_{2}(\mathrm{kPa})$ & $6.5 \pm 0.8$ & & $6.5 \pm 0.4$ & \\
\hline $\mathrm{PO}_{2}(\mathrm{kPa})$ & $2.7 \pm 0.4$ & & $2.9 \pm 0.4$ & \\
\hline Heart rate (beats/min) & $169 \pm 12$ & $169 \pm 16$ & $164 \pm 21$ & $184 \pm 30$ \\
\hline Central venous pressure $(\mathrm{mm} \mathrm{Hg})$ & $3.4 \pm 1.3$ & $3.6 \pm 1.5$ & $3.1 \pm 0.9$ & $2.6 \pm 1.1$ \\
\hline Mean arterial pressure $(\mathrm{mm} \mathrm{Hg})$ & $46.9 \pm 6.6$ & $47 \pm 4.9$ & $45.8 \pm 6.5$ & $43.3 \pm 1.9$ \\
\hline Hematocrit & $0.35 \pm 0.03$ & $0.35 \pm 0.02$ & $0.37 \pm 0.04$ & $0.42 \pm 0.04 \dagger$ \\
\hline
\end{tabular}

* Values are mean $\pm \mathrm{SD}$. For central venous pressure, $n=5$ saline fetuses and 5 ANP fetuses (twins); for mean arterial pressure, $n=6$ saline fetuses and 6 ANP fetuses (twins); for all other measurements, $n=8$ saline fetuses and 8 ANP fetuses (twins).

$\dagger p<0.005$ compared with ANP fetus at $0 \mathrm{~min}$ and to saline fetus (twin) at $50 \mathrm{~min}$.

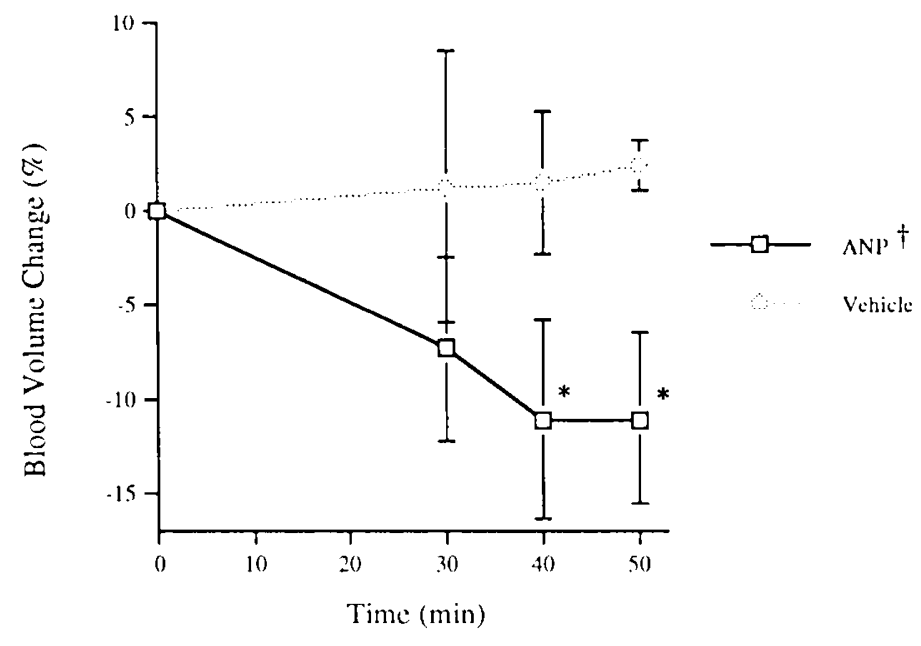

Fig. 2. Time course of the change of blood volume in 16 fetuses receiving either ANP or saline vehicle. Data are expressed as mean \pm $\mathrm{SD} ; n=8$ matched twin controls and 8 ANP fetuses. $\dagger$, ANP group time course is different from twin controls as determined by repeated measures analysis of variance $(p<0.001) ;{ }^{*}, p<0.03$ compared with time $0 \mathrm{~min}$ (within-group paired contrast).

\pm 0.58 versus $1.29 \pm 0.30$, respectively, $p<0.001$; albumin clearance $(n=55): 1091 \pm 1279$ versus $827 \pm 1464$, respectively, $p<0.01)]$. Specific tissue types were then matched to determine whether any regional vascular bed contributed to the overall ANP-induced increase in vascular albumin permeation (Fig. 3). TBIR was increased in most fetal tissues types after ANP, although a statistically significant difference could only be demonstrated in skin (all values ANP versus saline vehicle: $2.88 \pm$ 0.67 versus $1.55 \pm 0.35, p<0.02)$, muscle $(1.60 \pm 0.27$ versus $1.24 \pm 0.26, p<0.02)$, adrenal $(1.33 \pm 0.10$ versus $1.13 \pm 0.15$, $p<0.02)$, bone $(1.67 \pm 0.45$ versus $1.20 \pm 0.40, p<0.02)$, kidney ( $1.52 \pm 0.25$ versus $1.24 \pm 0.26, p<0.03)$, and gut $(1.69$ \pm 0.20 versus $1.39 \pm 0.34, p<0.03$ ). Albumin clearance was higher (ANP versus saline vehicle) in most tissues but reached statistical significance only in skin $(2135 \pm 944$ versus $775 \pm 847$ $\mathrm{nL} / \mathrm{g} / \mathrm{min}, p<0.05)$ and bone $(1012 \pm 1107$ versus $428 \pm 482$ $\mathrm{nL} / \mathrm{g} / \mathrm{min}, p<0.05)$.

\section{DISCUSSION}

The principal finding of this study is that ANP enhances vascular permeation of albumin in many fetal tissues. The amount of ANP administered had no hemodynamic effect but did have a marked influence on the hematocrit. Inasmuch as ANP does not change red blood cell volume (2), it seems to lower plasma volume partly through an effect on the microcirculation that is independent of urine flow $(5,6)$. The precise mechanism for this action cannot be ascertained from this investigation. The TBIR, an index of albumin permeation, may be influenced by various factors including tissue vascularity, rate of blood flow, blood pressure, and vascular porosity $(2,11)$. Hence, the mechanism for ANP-enhanced albumin permeation in fetal skin and other tissues might be through recruitment of vascular channels, increased capillary surface area, or increased regional blood flow. Alternatively, ANP might regulate protein transport itself by modulating either capillary pore size or lymphatic flow. Hydrostatic forces do not seem to play a role, inasmuch as neither venous nor arterial blood pressure was affected by the doses of ANP infused in this study.

ANP causes significant increases in albumin permeation in adult models $(2,12)$. However, the absolute values of fetal albumin clearance we observed in the control state were 5- to 20 -fold higher than those that Williamson ' $t$ al. (2) described in the adult rat. This finding is consistent with the observation that the capillary filtration coefficient in the fetal sheep is 5-10 times greater than in the adult (13). Thus, compared with the adult. the impact of ANP on fluid and protein movement in the fetus may be several orders of magnitude greater. Yet the fetal vascular compartment seems to be more stable than the adult vascular compartment. Fetal vascular compliance (14) is one half that of adult values, and the fetus may maintain blood volume within even closer limits than the adult when subjected to sudden volume expansion or contraction. After acute saline volume expansion, intravascular volume increased only $6-7 \%$ compared with $40 \%$ in adults receiving the same volume load (15). Thus, it would seem that decreased vascular compliance compared with the adult and the capacity to readily move fluid out of the fetal vascular compartment contribute to the stability of the fetal intravascular volume.

The observation by Brace and Gold (13) that the capillary filtration coefficient of the ovine fetus is greater after saline volume expansion compared with fetal hemorrhage supports the idea that the fetus can modulate capillary surface area. We speculate that ANP may be a mediator of this regulatory ability. When increasing blood volume increases cardiac filling, atrial myocyte stretch stimulates ANP secretion (16). Higher circulating ANP in turn reduces blood volume by increasing vascular fluid and protein permeation. By controlling the balance of the intravascular and extravascular fluid volume, ANP may serve to maintain the most advantageous relationship between cardiac filling and cardiac output, thereby optimizing cardiac function in the face of the normal rapid growth of the fetal blood volume.

Furthermore, alteration in albumin permeation through increased circulating ANP may contribute to the tissue edema seen in fetuses with severe anemia (8) and supraventricular tachycardia (10). Brace et al. (17) infused amounts of ANP similar to those used in the present study into fetal lambs and achieved circulating concentrations that ranged from 220 to $970 \mathrm{pmol} /$ $\mathrm{mL}$ ( 700 to $3000 \mathrm{pg} / \mathrm{mL}$ ), values that are higher than the physiologic range (17) but similar to values routinely found in clinical $(8,9)$ and experimental $(10)$ hydrops fetalis. It is interesting that we found ANP has its greatest effect on vascular permeation of skin, a tissue that is profoundly affected in hydrops fetalis and serves to define the syndrome itself (18). In the newborn lamb, 
A.

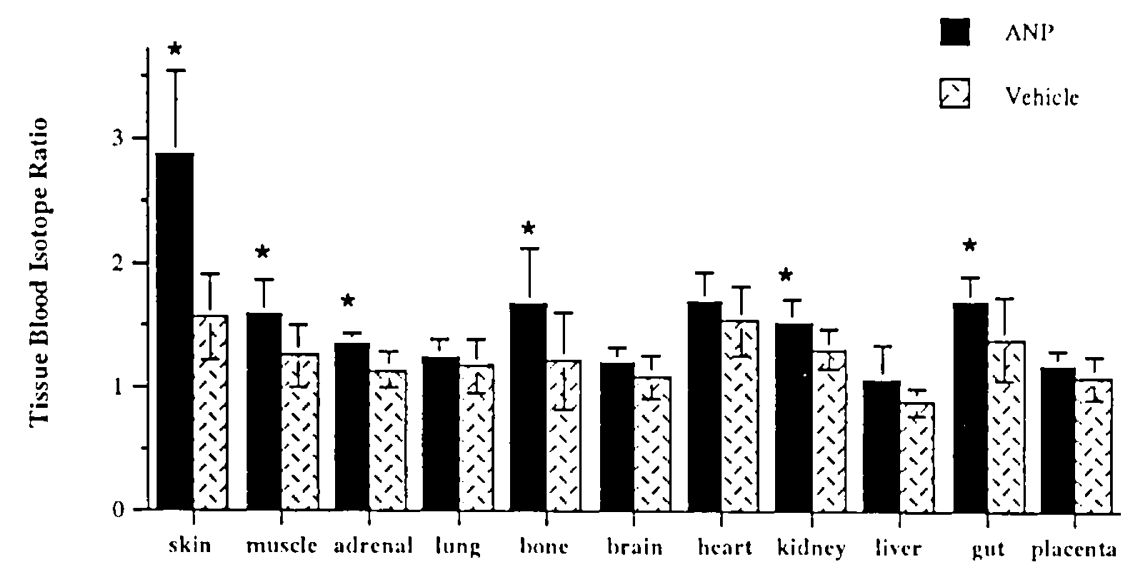

B.

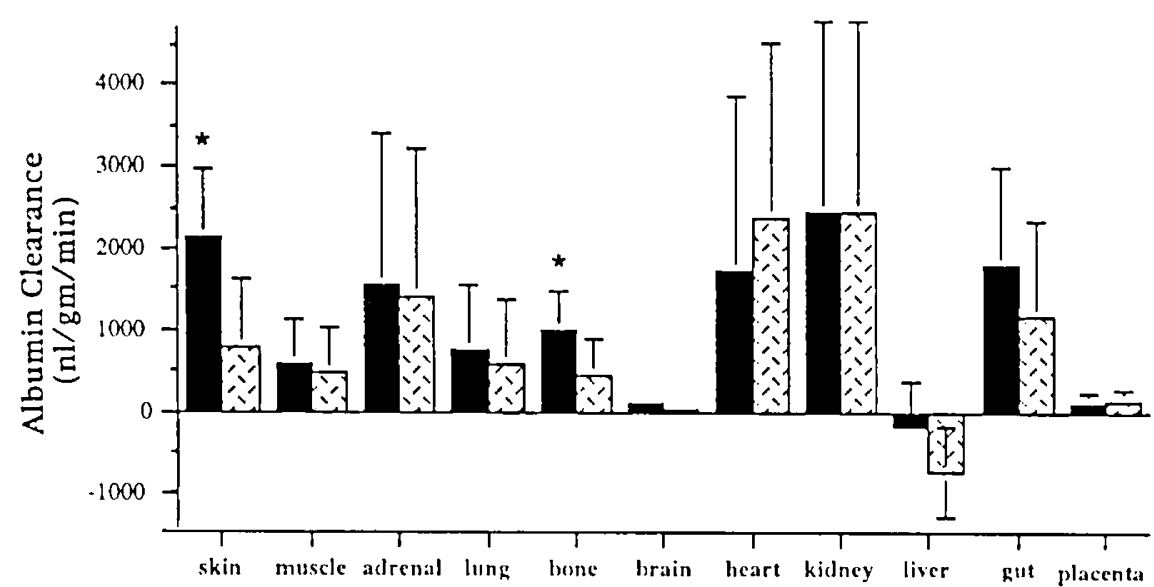

Fig. 3. Comparison of albumin permeation between fetuses receiving ANP and twins receiving saline vehicle. A, TBIR in seven ANP fetuses and seven saline fetuses. $B$, Albumin clearance in five ANP fetuses and five saline fetuses. ${ }^{*}, p<0.05$ compared with twin control (values are mean \pm $\mathrm{SD})$.

skin weight accounts for a significant portion of the total body weight, and in the chronically anemic newborn lambs, only skin weight was found to be increased (19). Thus, skin may be an important site of ANP-induced edema formation in the anemic newborn.

There are some statistical and methodologic limitations to our study. The fact that TBIR calculation is independent of tissue weight, a potential source of error in measurement, may partly account for the relatively smaller statistical variability compared with the albumin clearance data. In any case, given the small number of experiments and the overall variability within the data, few conclusions can be drawn from negative results. Tissues in which the null hypothesis would seem to be acceptable might actually reveal ANP effect given sufficient statistical power. For example, to be able to state with certainty (power $=80 \%$ ) that ANP had no effect on albumin permeation in brain or placenta, 47 and 182 experiments, respectively, would be required. Thus, the principle conclusions of the present study rely on the observation that ANP increases albumin permeation in some tissues, and no reliable conclusions can be derived where a difference could not be demonstrated. A methodologic aspect of our study also limits any conclusions on the basis of negative results. In tissues with a high degree of permeability, the lack of difference between ANP and saline fetuses may mean that $I_{b v}$ had equilibrated with the tissue during its 2-min circulation time, thus eliminating tissue versus blood differences. Only in tissues where differences were observed can valid conclusion be drawn. In this regard, it is reasonable that certain regional capillary beds that have open vascular fenestrations, such as the liver, might equilibrate rapidly with the blood, precluding the observation of a difference. It is interesting that consistent ANP effects (both TBIR and albumin clearance) were observed in bone, a tissue that in the adult has high permeability but in the fetus may, along with the skin, serve as a capacitance organ for the vascular compartment. It is unclear why albumin clearance in the liver was a negative value. This may be partly caused by error in measurement. Alternatively, it is possible that $\left(\mathrm{I}_{\mathrm{p}} / \mathrm{I}_{\mathrm{bv}}\right)_{\mathrm{t}}$ was lower than $\left(I_{p} / I_{b v}\right)_{b}$. This situation could occur if $I_{p}$ moved very slowly into the tissue, if the liver transported $I_{n}$ back to the blood, or if $I_{n}$ was sequestered in the lymphatic circulation.

In conclusion, overall vascular filtration is higher in the fetus than in the adult. Infusion of ANP causes fetal hemoconcentration, a decrease in blood volume, and enhancement of vascular permeation of albumin in most tissues, particularly fetal skin. These data support the hypothesis that the cardiac atria, by secreting ANP, may participate in blood volume regulation by maintaining a critical balance between the intravascular and extravascular fluid compartments. Dysregulation of the ANP secretory mechanism might culminate in the edema-forming syndrome known as fetal hydrops.

Acknowledgment. The authors thank Pat Renwick for her technical assistance and expertise.

\section{REFERENCES}

1. Burnett Jr JC, Kao PC, Hu DC, Heser DW, Heublein D, Granger JP, Opgenorth TJ, Reeder GS 1986 Atrial natriuretic peptide elevation in congestive heart failure in the human. Science 321:1145-1147

2. Williamson JR. Holmberg SW, Chang JM. Sutera SP. Needleman P 1989 Mechanisms underlying atriopeptin induced increases in hematocrit and vascular permeation in rats. Circ Res 64:890-899 
3. Almeida Fa. Suzuki M, Maack T 1989 Atrial natruiretic factor increases hematocrit and decreases plasma volume in nephrectomized rats. Life Sci 39:1139-1199

4. Fluckiger JP, Waeber B, Matsueda G, Delaluye B, Nussberger J, Brunner HR 1986 Effect of atriopeptin III on hematocrit and volemia of nephrectomized rats. Am J Physiol 251:H880-H883

5. Brace RA, Bayer LA. Cheung CY 1989 Fetal cardiovascular, endocrine, and fluid responses to atrial natriuretic factor infusion. Am J Physiol 257:R580R587

6. Robillard JE, Nakamura KT, Varille VA, Andresen AA, Matherne GP. Vanorden DE 1988 Ontogeny of the renal response to natriuretic peptide in sheep. Am J Physiol 254:F634-F641

7. Clark EB 1990 Growth, morphogenesis, and function, the dynamics of cardiac development. In: Moller JH, Neal WA (eds) Fetal, Neonatal, and Infant Cardiac Disease. Appleton \& Lange. Norwalk, CT, pp 3-23

8. Moya FR, Grannum P. Riddick L. Robert JA, Pinheiro R 1990 Atrial natriuretic factor in hydrops fetalis caused by $R h$ isoimmunisation. Arch Dis Child 65:683-686

9. Robillard JE, Weiner C 1988 Atrial natriuretic factor in the human fetus: effect of volume expansion. J Pediatr 113:552-555

10. Nimrod C. Deane P, Harder J, Davies D, Kondo C, Takahashi Y, Wong T, Maloney J, Nicholson S 1988 Atrial natriuretic peptide production in association with nonimmune hydrops. Am J Obstet Gynecol 159:625-628
11. Kilzer P, Chang K, Marvel J, Kilo C, Williamson JR 1985 Tissue differences in vascular permeability changes induced by histamine. Microvasc Res 30:270-285

12. De Vries PJF, Tyssen CM, Struyker-Boudier. Smits JFM 1990 Atrial natriuretic factor increases albumin extravasation in conscious rats. Pllugers Arch 415:507-509

13. Brace RA, Gold PS 1984 Fetal whole-body interstitial compliance, vascular compliance, and capillary filtration coefficient. Am J Physiol 247:R800 R805

14. Gilbert RD, Genstler CC. Dale PS, Power GG 1981 Compliance of the fetal sheep liver. J Dev Physiol 3:283-295

15. Brace RA 1983 Fetal blood volume responses to intravascular saline solution and dextran. Am J Obstet Gynecol 147:777-781

16. Edwards BS, Zimmerman RS. Schwab TR, Heublein DM, Burnett JC 1988 Atrial stretch, not pressure, is the principal determinant controlling the acute release of atrial natriuretic factor. Circ Res 62:191-195

17. Brace RA. Cheung CY 1987 Cardiovascular and fluid responses to atrial natriuretic factor in sheep fetus. Am J Physiol 253:R561-R567

18. Machin GA 1989 Hydrops revisited: literature review of 1.414 cases published in the 1980s. Am J Med Genet 34:366-390

19. Bernstein D. Teitel DF, Rudolph, AM 1988 Chronic anemia in the newborn lamb: cardiovascular adaptations and comparison to chronic hypoxemia. Pediatr Res 23:621-627 